\title{
2 \\ An Approach to Spatial Urban Land Use Change for Hydrologic Modeling
}

Daniel T. McGrath

As the metropolitan regions of North America continue to expand, there is a growing recognition of the need to forecast land use change and urbanization patterns over longer time frames - so that regional environmental and hydrologic consequences can be forecast and the consequences of different development scenarios compared. Unfortunately there are obstacles to achieving such forecasting capability, including that of integration of spatial environmental/ hydrological modeling and spatial economic modeling, and the econometric problems associated with estimating spatial economic changes. Existing models of land use change fail to adequately incorporate the complex interactions between economic and environmental factors as a metropolitan region urbanizes. This chapter presents a discussion of some of the recognized difficulties in combining the relevant disciplines involved in producing accurate long-range forecasts of land use change. It also presents one possible approach to the development of a spatial land use change model.

\subsection{Introduction}

Over the past 50 years, North American urban development has converted an ever-increasing amount of land area per capita. There is little debate that this expansion has produced enormous changes to the environmental quality and hydrological function within and at the fringe of metropolitan regions. Particularly

McGrath, D.T. 2001. "An Approach to Spatial Urban Land Use Change for Hydrologic Modeling." Journal of Water Management Modeling R207-02. doi: 10.14796/JWMM.R207-02.

(C) CHI 2001 www.chijournal.org ISSN: 2292-6062 (Formerly in Models and applications to Urban Water Systems. ISBN: 0-9683681-4-X) 
evident are the elements of surface and groundwater degradation that are associated with the increases in impervious surface cover associated with land use change. As land is converted to urban use, runoff to surface water is increased and groundwater recharge is reduced. For example, about $40 \%$ of precipitation on undeveloped/natural land is typically returned back to the atmosphere with about $10 \%$ to surface runoff and $50 \%$ to soil and groundwater (USEPA, 1993). However, when natural land is cleared and covered with typical urban impermeable surfaces patterns, infiltration drops to less than 15\% and runoff can increase up to $85 \%$ (Hough, 1995). Drainage systems and modified channels, designed to expedite the increased runoff in urban areas often exacerbate flooding downstream during extreme weather events. In addition to changes in flow patterns, increases in impervious land cover increase the velocity and flow rate of pollutant loading in runoff to surface water and groundwater recharge, as a wide range of pollutants are typically deposited onto urban surfaces exposed to precipitation. Many of the contaminants can persist in groundwater for significant lengths of time. As nearly $75 \%$ of major U.S. metropolitan areas depend heavily on groundwater for their water supply (Spulber, 1998), increases in metropolitan land areas are likely to further withdraw groundwater at an unsustainable rate and increase the risk of groundwater contamination. In coastal areas, excessive withdrawals of groundwater have been directly associated with saltwater intrusion of aquifers and destructive ground subsidence.

Table 2.1 identifies the historical increases in urban land area and the land area per capita in acreage, both ranked by the change from 1950 to 1990, of the 19 largest coastal (oceanic and great lakes) metropolitan regions in the United States as identified by the U.S. Census Bureau. On average, urban land use has increased from 0.10 acres $(0.04 \mathrm{ha})$ per capita to 0.16 acres $(0.07 \mathrm{ha})$ per capita. From 1950 to 1990 these 19 cities expanded their urbanized areas nearly 11,000 square miles $\left(28,500 \mathrm{~km}^{2}\right)$ - from 5,500 square miles $\left(14,200 \mathrm{~km}^{2}\right)$ to 16,400 square miles $\left(42,400 \mathrm{~km}^{2}\right)$. While most cities decreased remarkably in overall density, there were a few cities that showed slight increases in density. Interestingly, these metropolitan regions were some of the fastest growing in the U.S.: Los Angeles, San Diego, Miami, Fort Lauderdale, and Tampa-St. Pete. Despite these regions' slight increases in overall density, they accounted for in total nearly one quarter of the total increase in land area, expanding 2,700 square miles $\left(7,000 \mathrm{~km}^{2}\right)$ from 1950 to 1990 . Year 2000 land area totals are not yet available for these cities, but rough estimates for year 2000 identify that these 19 metropolitan regions have expanded an additional 1,600 square miles $(4,100$ $\mathrm{km}^{2}$. The coastal city with the greatest physical expansion was Norfolk, VA, which increased its per capita land use from 0.103 in 1950 to an enormous 0.32 in 1990. 
Table 2.1a U.S. coastal metropolitan statistical urbanized land areas in square miles, ranked by the change from 1950 to 1990 .

\begin{tabular}{rllllllll} 
Rnk & $\begin{array}{l}\text { Urbanized } \\
\text { Area }\end{array}$ & 1950 & 1960 & 1970 & 1980 & 1990 & $\begin{array}{l}\text { Est. } \\
2000\end{array}$ & $\begin{array}{l}\text { Change } \\
1950-90\end{array}$ \\
\hline 1 & New York & 1,253 & 1,892 & 2,425 & 2,808 & 2,967 & 3,126 & 1,714 \\
2 & Los Angeles & 871 & 1,370 & 1,572 & 1,827 & 1,966 & 2,105 & 1,095 \\
3 & Houston & 270 & 431 & 539 & 1,049 & 1,177 & 1,305 & 907 \\
4 & Chicago & 708 & 960 & 1,277 & 1,498 & 1,585 & 1,672 & 877 \\
5 & Washington & 178 & 341 & 495 & 807 & 945 & 1,083 & 767 \\
6 & Norfolk & 62 & 109 & 299 & 418 & 664 & 910 & 602 \\
7 & S.F.-Oakland & 287 & 572 & 681 & 796 & 874 & 952 & 587 \\
8 & San Diego & 133 & 276 & 381 & 611 & 690 & 769 & 557 \\
9 & Boston & 345 & 516 & 664 & 857 & 891 & 925 & 546 \\
10 & Tampa-St. P. & 180 & 218 & 291 & 527 & 650 & 773 & 470 \\
11 & Seattle & 123 & 238 & 413 & 485 & 588 & 691 & 465 \\
12 & Baltimore & 152 & 220 & 310 & 523 & 593 & 663 & 441 \\
13 & Milwaukee & 102 & 392 & 457 & 496 & 512 & 528 & 410 \\
14 & Cleveland & 300 & 587 & 646 & 629 & 636 & 643 & 336 \\
15 & Portland & 114 & 192 & 267 & 349 & 388 & 427 & 274 \\
16 & Miami & 117 & 183 & 259 & 340 & 353 & 366 & 236 \\
17 & Ft Lauderdale & & 124 & 212 & 289 & 327 & 365 & 203 \\
18 & Buffalo & 123 & 160 & 214 & 266 & 286 & 306 & 163 \\
19 & New Orleans & 222 & 267 & 184 & 230 & 270 & 310 & 48 \\
& Total & 5,540 & 9,048 & 11,586 & 14,805 & 16,362 & 17,919 & 10,822 \\
& Average & 308 & 476 & 610 & 779 & 861 & 943 & 563
\end{tabular}

Table 2.1b U.S. coastal metropolitan statistical land area per capita in square miles, ranked by the change from 1950 to 1990 .

\begin{tabular}{|c|c|c|c|c|c|c|c|}
\hline Rank & Urbanized Area & 1950 & 1960 & 1970 & 1980 & 1990 & $\begin{array}{l}\text { Change } \\
1950- \\
1990\end{array}$ \\
\hline 1 & Norfolk & 0.103 & 0.137 & 0.286 & 0.347 & 0.321 & 0.218 \\
\hline 2 & Milwaukee & 0.079 & 0.218 & 0.234 & 0.263 & 0.267 & 0.189 \\
\hline 3 & Baltimore & 0.084 & 0.099 & 0.126 & 0.191 & 0.201 & 0.117 \\
\hline 4 & Boston & 0.099 & 0.137 & 0.160 & 0.205 & 0.205 & 0.107 \\
\hline 5 & Cleveland & 0.139 & 0.210 & 0.211 & 0.230 & 0.243 & 0.104 \\
\hline 6 & Buffalo & 0.088 & 0.097 & 0.126 & 0.170 & 0.192 & 0.104 \\
\hline 7 & Washington & 0.089 & 0.121 & 0.128 & 0.187 & 0.180 & 0.091 \\
\hline 8 & Seattle & 0.127 & 0.176 & 0.214 & 0.223 & 0.216 & 0.089 \\
\hline 9 & Portland & 0.142 & 0.188 & 0.207 & 0.218 & 0.212 & 0.070 \\
\hline 10 & S.F.-Oakland & 0.091 & 0.151 & 0.146 & 0.160 & 0.154 & 0.063 \\
\hline 11 & Chicago & 0.092 & 0.103 & 0.122 & 0.141 & 0.149 & 0.057 \\
\hline 12 & New York & 0.065 & 0.086 & 0.096 & 0.115 & 0.118 & 0.053 \\
\hline 13 & Houston & 0.247 & 0.242 & 0.206 & 0.278 & 0.260 & 0.013 \\
\hline 14 & San Diego & 0.197 & 0.211 & 0.204 & 0.229 & 0.188 & -0.009 \\
\hline 15 & Los Angeles & 0.139 & 0.135 & 0.120 & 0.123 & 0.110 & -0.029 \\
\hline 16 & Tampa-St. Pete & 0.282 & 0.223 & 0.216 & 0.249 & 0.243 & -0.039 \\
\hline 17 & Miami & 0.163 & 0.137 & 0.136 & 0.135 & 0.118 & -0.045 \\
\hline 18 & New Orleans & 0.215 & 0.202 & 0.122 & 0.137 & 0.166 & -0.049 \\
\hline \multirow[t]{2}{*}{19} & Fort Lauderdale & & 0.248 & 0.221 & 0.183 & 0.169 & -0.079 \\
\hline & Average & 0.101 & 0.128 & 0.136 & 0.162 & 0.161 & 0.060 \\
\hline
\end{tabular}


It is extremely difficult to accurately translate population or employment growth forecasts into increases in urban land area for a metropolitan region. However, if these 19 coastal cities continue to expand at the current average rate per capita, to accommodate the U.S. Census Bureaus estimated 2025 population growth for these 19 metropolitan regions of between 17 and 22 million people, these 19 regions will likely add another 4,600 to 5,800 square miles (1200 $1500 \mathrm{~km}^{2}$ ) to their urban land areas. This increase assumes that these cities will continue to utilize land at the 1990 average of 0.16 gross acres per capita. These figures are presented only as a very rough estimate and are certainly not meant to be an accurate spatial forecast. However, the figures are quite large and are presented to underscore the pressing need for accurate spatial forecasts of urbanization patterns if the debate over environmental quality and natural capital preservation within urban areas is to be extricated from its current crisis mode.

Despite the growing awareness of the water resource and water quality problems created by urbanization, especially in controlling non-point source runoff, the relationship between expanding regional economies and the regional hydrological resources on which they depend is complex and not fully understood. Most assessments of the hydrological impacts of land use change are performed on an event-specific basis. Producing science-based, regionalscale, long-term forecasts of the hydrological consequences of urban growth is not currently possible (Bockstael and Irwin, 1999). This limits local and regional land use policymakers from fully comparing and contrasting the environmental and hydrological consequence of one urban growth scenario against another. This chapter presents a discussion of current developments in land use change forecasting and presents a theoretical framework to estimate a highly disaggregated, spatial land use change model. This framework incorporates the polycentric patterns of current North American metropolitan land use and has the capacity to incorporate the regional hydrological features, as well as the political and non-economic factors, that may determine land value and subsequently may be a determinant of land use change.

\subsection{Current Practice in Land Use Change Modeling}

Recent years have seen some improvement in the capability to translate regional economic developments into spatial land use change patterns. However, relatively little progress has been made in integrating environmental factors, specifically hydrological patterns and factors, into spatial land use change models. One key challenge has been producing models that utilize, in a meaningful way, the same spatial level of detail. Another is explicitly 
incorporating the economic behavior of land investors/developers that seeks to capture real economic profit through redevelopment of a site to a new use.

Bockstael and Irwin (1999) provide a thorough recent summary of both economic and landscape ecology approaches to modeling changes in urbanization patterns and their relative usefulness in predicting regional ecologic and environmental consequences of urban growth. In general, the economics discipline has not made a serious effort to push forward the modeling of spatially explicit land use change. These authors conclude that most extant spatial economic models cannot predict land use pattern changes at as high a level of resolution as landscape change models. Spatial economic models ignore the spatial heterogeneity that is central to scientific inquiry mostly because economic models are designed to explore social impacts rather than environmental ones and also because they are confined by severe spatial data limitations.

Most of the efforts to model land use change come from the landscape ecology discipline using a variety of spatial modeling techniques with the explicit goal of forecasting environmental and hydrological consequences. Most commonly, models represent the landscape as a two-dimensional "mosaic" of grid cells, and predict land use change based on extending previous spatial pattern trends (Tim et al., 1992; Harbor, 1994; Muller and Middleton, 1994; Adamus and Bergman, 1995; McClintock et. al., 1995; Pijanowski et al., 1996; Bhaduri et al., 1997). These models can be very complex with respect to spatial ecological factors. Unfortunately, according to Bockstael and Irwin, they are unacceptably simplistic with regard to the human factors that fundamentally determine land use change. While some landscape change models have made an effort to incorporate the human dimension by including "socio-economic" variables as model drivers (LaGro and DeGloria, 1992; Liu et al., 1993; Mertens and Lambin, 1997), there are no existing landscape change models that incorporate the structural economic process that determines land use change - the capture of real economic profit by private market developers. Because of this failure to incorporate the underlying structure of the land use change process, most economists take the view that it is likely these models may lead to incorrect policy conclusions. The simple approach taken by most landscape ecology models of land-use change is likely due to, in part, the enormous availability of spatially disaggregate land cover data, mostly from satellite imagery, and the lack of economic data at similar spatial scales.

There are, however, two recent exceptions. The first is a land use change model developed by Landis (1995). Landis' California Urban Futures (CUF) model, designed to evaluate the spatial consequences of local land use alternatives in the greater San Francisco Bay Area, is the only existing urban land use change simulation model that explicitly models the disequilibrium process 
of private development decisions (i.e. profit capture through land use change). Additionally, the CUF model is the first regional land use change simulation model that utilizes GIS for data integration and spatial analysis. This enables the model to predict land use change at a very spatially disaggregated scale, though the landscape "cells" do not directly correspond to legal land parcels. The high spatial resolution of the model makes it one of the few economics-based models that can provide land use change input to environmental impact models. The CUF model first utilizes empirically estimated econometric models to predict future household and employment projections by jurisdictions. Then it utilizes a multinomial logit model to estimate the probability of land use change as a function of a variety of site and community characteristics that directly relate to land value. The households and employment are allocated to the "developable" cells that have the highest probabilities of transition based on their profit potential. There are some limitations to the CUF model. Particularly, the CUF model can only allocate residential land use change, and important factors such as zoning and explicit hydrological infrastructure variables are excluded from the profit potential calculation. The CUF model is not, however, devoid of any investigation of hydrological structure. The developable land units (DLUs) are determined spatially, based on overlaying of maps that may exclude certain land from development, and a wetland layer is one spatial overlay. Also, in determining the profit potential on a given DLU, "Service Extension Costs" and "Extraordinary infrastructure capacity costs and impact mitigation costs" are included as a variable. Such costs could include costs to extend water service and sewer capacity, though they are not explicitly mentioned by the author.

Lastly, the CUF model is not an equilibrium model. Therefore, any excess demand for housing is not translated into land value and thus the profit potential determining population allocation.

A second important economics-based land use change model is that developed by Bockstael (1996), which seeks to model regional groundwater quality consequences of land use change within the Patuxent River watershed on the Chesapeake Bay. This model is the first land use change model that is fundamentally based on bid-rent theory - the one theoretical approach within economics that is spatial. Bockstael's equilibrium approach recognizes that the likelihood that a parcel of land will be converted from agricultural use to residential use is a function of the profit gains to be made through conversion - that is, the difference in value between a parcel's new use and its current use. This model is of sufficient spatial disaggregation to facilitate the forecasting of regional-scale patterns of nitrogen loading to groundwater that result from two hypothetical sewer service infrastructure development scenarios. An important contribution of Bockstael's model is that it explicitly identifies the important connection between land use change and access to water supply and sewage 
infrastructure - evidence that underscores the need to fully understand the relationship between hydrologic infrastructure, both built and natural, and land use change within a given region. In addition, Bockstael importantly recognizes that the empirical approach to modeling land use change - a combined use of probit and ordinary least squares estimation techniques - has two econometric problems that seriously compromise the validity of the empirical results: selection bias and spatial autocorrelation.

When econometric models are used to estimate value of land in a certain use, such as residential use, only land in that type of use can be used to estimate the model. It may be possible that variables that determine that transition from agricultural use to residential use are not observed. This is what is meant by selection bias. Spatial autocorrelation arises because it is possible that any omitted variables are spatially correlated, as a variable of any significance is likely to have a correlation with the same variable of an adjacent parcel. There are statistical methods to correct for selection bias. Unfortunately, there are presently no econometric methods to adequately correct for spatial autocorrelatio. (Bockstael, 1996).

\subsection{The Urban Economic Approach to Modeling Land Use Change}

The important contribution of both Landis' and Bockstael's work is their respective development of approaches linking spatial environmental impact models with a land use change modeling that is based on changes in land value which, in turn, are based on the regional and local spatial characteristics. These spatial characteristics determine how investors might identify profit opportunities by investing in the fixed capital to produce land use change. However, the dynamic process of how changes in land value relate to changes in land use patterns is a complex process and not an easy one to directly model given that the process is essentially a disequilibrium one. In this process, investors/ developers seek to capture real economic profit through the land market's response to the change in, or the addition of, fixed capital on any given parcel of land. However, as will be discussed below, the capture of profit through land use change/redevelopment is the dominant and most important mechanism by which population and employment expand and thus land changes use, particularly at the urban fringe.

Within the body of urban economic literature, Brueckner (1980) and Wheaton (1981) began independently to develop spatial growth models of metropolitan areas in response to the inadequacies of the static equilibrium 
models of urban land use in describing growth or change in the urban structure. The optimal redevelopment rule identified by Brueckner (1980) states that the development or redevelopment of any parcel will take place when the value of the parcel converted to a new use net of the conversion costs exceeds the value of the same parcel remaining in its current use - that is, when there is a positive value differential on the given parcel. Value differential theory has been strongly supported empirically by three recent studies (Rosenthal and Helsley, 1995; Munneke, 1996; McGrath, forthcoming).

Spatial scale economies are the principal cause for spatial concentration of employment and population within a metropolitan region, the most important being agglomeration economies (O'Sullivan, 1996). Agglomeration economies refer to cost reductions that occur due to locating in proximity to other firms. Agglomeration economies operate over the entire urban area, and it is these economies that generate the complex polycentric concentrations in employment (and subsequently population) that we now see in North American metropolitan regions. A location that is well served by the urban transportation infrastructure may attract firms even when the firms have no other reason to locate near one another. Additionally, firms may also enjoy cost savings simply by locating near one another. Proximity to other firms may lower production costs by simplifying personal communication or may help customers in reducing their shopping costs. Thus the initial location of a suburban subcenter may be the result of access to the urban transportation network, but the additional economies can provide an independent motivation for urban subcenter formation.

McMillen and McDonald (1998a, 1998b) have recently developed an innovative method for the spatial modeling of employment and population patterns that characterize polycentric metropolitan regions - methods that hold promise in assisting the development of more accurate land use change forecasting models. Specifically, these authors show that, utilizing the most recent maximum likelihood techniques, the gross population and employment densities in a zone, and the likelihood that the zone will contain population and employment, can be jointly determined given the characterization of the zone's transportation accessibility, sub-center proximity, and other characteristics that would determine land value. This relationship can be expressed most generally as:

where:

$$
\left\{D_{E, P}, \Psi_{E, P}\right\}=f[A, S, C]
$$

$D_{E, P}=$ employment and population density respectively,

$\Psi_{E, P}=$ the likelihood that a zone will contain either employment or population respectively,

$A=$ the vector of transportation accessibility variables, 


$$
\begin{aligned}
S= & \text { the vector of employment sub-center proximity, and } \\
C= & \text { the vector of other idiosyncratic variables determin- } \\
& \text { ing land value. }
\end{aligned}
$$

Using spatial employment and population data for the Chicago metropoli$\tan$ region, these authors have shown that this approach accurately determines static spatial measurements of both the densities of employment and population at the quarter section level using the spatial characteristics of the quarter section as independent variables. In most of the United States, a quarter section is 0.25 square miles, 160 acres or about 65 hectares. Given that metropolitan Chicago is approximately 1,600 square miles, a quarter section is less than $0.02 \%$ of the region. These authors also provide empirical evidence distinguishing between the two agglomeration economies of transportation proximity and urban subcenter proximity. A significant advantage of this sophisticated reduced-form modeling approach, based fundamentally on bid rent theory, is that its utilization of maximum likelihood estimation procedures avoids the selection bias problem inherent in other econometric modeling approaches.

In addition to the important influences of the two above-discussed agglomeration economies - transportation accessibility and employment subcenter proximity - on land value, the natural and built hydrological features of a site also determine a significant share of a site's development costs which may be capitalized into land value. There are a few studies that identify water service and sewer service infrastructure as a determinant of land value (Dunford et al., 1985; Vaillamont \& Monty, 1985). In Bockstael's work discussed above (Bockstael, 1996) one of the determinants of land value, and thus one of the determinants of land use change, is the parcel's connection to the water service infrastructure. However, there are no recent investigations within the urban economic literature that explore the systematic contribution of the built and natural hydrological features to aggregate metropolitan structure (Anas, personal communication).

\subsection{The Land Use Change Modeling Approach}

The reduced-form approach to modeling land use change presented here follows closely the theoretic approach outlined by McMillen and McDonald (1998a, 1998b) to determine spatial patterns of gross population and employment density. Integral to their framework to determine density patterns, is a secondary framework to determine the share of land in a given use to the total land in a zone. Following this approach, assume that there are only two land uses in an urban area, residential and employment (commercial and industrial 
use). A residential bid rent function represents the maximum amount that a household (and subsequently a profit- maximizing firm providing housing) will bid for a unit of land as a function of parcel characteristics, holding utility constant. The employment bid rent function is defined the same way, only that it holds profit constant.

In addition to the above described transportation accessibility and employment subcenter proximity vectors, empirical bid rent functions must also include idiosyncratic parcel characteristics, such as natural landscape features or social factors such as race, that may influence land markets. This chapter hypothesizes that the built and natural hydrological features of any given location are likely to be significant determinants of both residential and employment bid rents. Specifically, these features would be:

1. access to the built water and sewer service infrastructure system, including water and sewer service prices and local capacity limitations denoted $W_{B}$, and

2. natural hydrological resource features such as groundwater resource characteristics and sustainable supply capacities and surface water resource characteristics and flow capacity, denoted as $W_{N}$.

Combining the observable bid rent function arguments as the vector $X=$ $\left(A, S, W_{B}, W_{N}\right.$ ) the bid rent function are written as:

$$
\begin{array}{ll}
\ln R_{R}=\beta_{R} X+u_{R} & \text { for residential land use, and } \\
\ln R_{E}=\beta_{E} X+u_{E} & \text { for employment use, }
\end{array}
$$

where $u_{R}$ and $u_{E}$ are normally distributed error terms. The vector $X$ does not need a subscript because characteristics that affect value in only one use can be assigned a coefficient value of zero in the other.

Assume that the amount of land in a given zone rises with the difference between residential and employment land values. However, land use is also determined by non-economic factors such as zoning, denoted by the vector $Z$. Thus the following expression applies when the amount of land in a zone in residential use is non-zero, or when $L_{R}>0$ :

where:

$$
\ln \left(L_{R} / L\right)=\theta\left(\ln R_{R}-\ln R_{E}\right)+\tau Z+\varepsilon,
$$

$$
\begin{aligned}
L_{R} / L= & \text { the share of land in the zone in residential use, } \\
R_{R}= & \text { the rent in residential use, } \\
R_{E}= & \text { the rent in employment use, } \\
Z= & \text { the vector of non-economic variables determining the } \\
& \text { share of land in residential use such as zoning, and }
\end{aligned}
$$




$$
\varepsilon=\text { a normally distributed error term. }
$$

To simplify notation, the subscript $i$ denoting multiple zones in a region has been omitted.

Substituting the bid rent functions in Equation 2.2, we obtain:

$$
\ln \left(L_{R} / L\right)=\theta\left(\beta_{R}-\beta_{E}\right) X+\tau Z+\theta\left(u_{R}-u_{E}\right)+\varepsilon .
$$

Equation 2.3 can be simplified to the following expression:

$$
\ln \left(L_{R} / L\right)=\gamma_{R} X+\eta
$$

where:

$X$ is redefined as the vector $X=\left[A, S, W_{N} W_{B}, Z\right]$, and

$$
\eta=\theta\left(u_{R}-u_{E}\right)+\varepsilon
$$

A similar derivation can be done for land in employment use. Equation 2.4 only applies for zones that have land in residential use. The decision to convert land to residential use in a zone that does not have any land in residential use is likely to be determined by the same factors that determine the share of land in residential use and the factors that account for the decision to zone land residential. Thus, it is a reasonable assumption that the likelihood that a zone contains residential land is a function of the same variables that determine the share of land in residential use, though there is no reason to assume that the coefficients should be the same. Thus

$$
\operatorname{Prob}(R=1)=\Phi\left(\mu X / \sigma_{\eta}\right)
$$

where:

$$
\begin{aligned}
& \Phi=\text { the cumulative normal density function and } \\
& \sigma_{\eta}=\text { the variance of } \eta .
\end{aligned}
$$

As previously discussed the problem of selection bias is avoided if Equations 2.4 and 2.5 are jointly estimated using maximum likelihood procedures. Thus in its most general form, the expression to be estimated is:

$$
\left\{L_{E, R}, L ; \Psi_{E, R}\right\}=f\left[A, S, W_{N}, W_{B}, Z\right]
$$

The share of land in residential use and in employment use and the probabilities that a zone will contain land in residential or employment use is a function of the vector of parcel characteristics determining land value and idiosyncratic characteristics of the zone, such as zoning and the hydrological characteristics of the zone. 
Given the estimation of Equation 2.6 for two time periods, $t 1$ and $t 2$, it then becomes a simple matter to model changes in land use shares. This is most easily determined by expressing the change as the ratio of land in one use in time period 2 to land in the same use in time period 1 . For residential use this would be the ratio, $L_{R t 2} / L_{R t 1}$. Multiplying by $L / L$ (which is the total land area within a zone, this expression can be written as $\left(L_{R t 2} / L\right) /\left(L_{R t 1} / L\right)$. Taking the natural $\log$ of this expression, we obtain:

$$
\begin{aligned}
& \ln \left(L_{R t 2} / L\right) /\left(L_{R t I} / L\right) \\
= & \ln \left(L_{R t 2} / L\right)-\ln \left(L_{R t I} / L\right) \\
= & \left(\gamma_{R} X+\eta\right)_{t 2}-\left(\gamma_{R} X+\eta\right)_{t 1}
\end{aligned}
$$

Assume that the vector of explanatory vector, $X=\left[A, S, C, W_{N^{b}} W_{B}, Z\right]$, can be divided into two groups of variables: those that do not change over the two time periods, such as natural hydrological features and proximity to suburban subcenters denoted as $Y$, and those that do change over the two time periods due to changes in the built urban infrastructure, such as changes in a zone's transportation accessibility, changes in a zone's access to municipal water supply and sewer infrastructure, and/or changes in zoning, denoted as $X^{*}$. Thus, given that Equation 2.6 is estimated for a region for two separate time periods, $t 1$, and $t 2$, a spatial estimate of the market-driven change in land in residential use, expressed as the ratio of land in that use over two time periods, $t 2$ and $t 1$, can be rewritten as:

$$
\ln \left(L_{R t 2} / L_{R t}\right)=\left(\gamma_{R t 2}-\gamma_{R t}\right) Y+\gamma_{R t 2} X_{t 2}^{*}-\gamma_{R t 1} X_{t 1}^{*}
$$

and an expression for land in employment use is similarly derived as:

$$
\ln \left(L_{E t 2} / L_{E t}\right)=\left(\gamma_{E t 2}-\gamma_{E t}\right) Y+\gamma_{E t 2} X_{t 2}^{*}-\gamma_{E t 1} X_{t 1}^{*}
$$

Equations 2.8 and 2.9 allow one to estimate the market-driven residential and employment land use change response to a hypothetical infrastructure development scenario. Assume that $X_{t l}^{*}$ represents determining zone characteristics today in year 2000 and $X^{*}{ }_{t 2}$ represents a forecast for determining zone characteristics at some future point in time, say 2010. Thus, Equations 2.8 and 2.9 can provide directly an estimate for the amount of land in any zone within a region in residential and employment use as determined by the private market in the year 2010, without having to allocate population and employment directly to the zone. When estimates of land use change for a zone are combined with similar estimates of a zone's employment and population densities, derived in 
a similar manner, an accurate spatial forecast of urban structure can be facilitated from a regional economic forecast for a metropolitan area given any hypothetical transportation and hydrological infrastructure scenario for the area. The land use change forecast would then provide input to spatial environmental quality impact models. Ideally, a portfolio of impact models could be applied and regional-scale environmental impacts of hypothetical regional development scenarios could be compared and contrasted.

\subsection{Conclusion}

The goal of this chapter is to present a framework, consistent with urban economic theory, to empirically estimate the connection of metropolitan land use change - as manifested in changes in a zone's share of land to a given use - to the relevant built and natural hydrological features that may be capitalized into land value. The theoretical framework presented above extends existing land use change modeling in two major ways. First, it significantly improves the urban economic bid-rent-based approach to land use change by incorporating recent developments in urban economic theory and econometric modeling that avoid the selection bias problem. Also, being an equilibrium approach, it avoids some of the theoretical problems associated with trying to directly model the disequilibrium process of how investors/redevelopers capture economic profit through land development. Second, it expands the urban economic approach to incorporate both the built and natural hydrological infrastructure and features as determinants of urban structure and land use change, and it is this aspect which makes the approach interdisciplinary. Achieving an empirically estimated model of land use change for a metropolitan region will require having an accurate, highly-disaggregated, spatial characterization of an urban region's built and natural hydrological features over two time periods, consistent with spatial measurements of land use shares over the same time periods. Characterizations of urban regions are likely to be only available within the urban hydrological modeling discipline.

\section{References}

Adamus, C. L. and M. J. Bergman. 1995. Estimating non-point source pollution loads with a GIS screening model. Water Resources Bulletin 31: 647-655.

Bhaduri, B., M. Grove. C. Lowry, and J. Harbor. 1997. Assessing the long-term hydrologic impact of land use change. Journal of the American Water Works Association 89(11): 94-106. 
Bockstael, N. E. 1996. Modeling economics and ecology: the importance of a spatial perspective. American Journal of Agricultural Economics 78 (December): 11681180.

Bockstael, N. and E. Irwin, 1999. Economics and the land use-environment link. Draft prepared for the 2000 Yearbook of Environmental Economics, Tietenberg and Folmer (eds.).

Brueckner, J. K. 1980. A vintage model of urban growth. Journal of Urban Economics 8:389-402.

Dunford, R.C., C. Marti, and M. Mittelhammer. 1985. A case study of rural land prices at the urban fringe including buyer expectations. Land Economics 61: (February): 42-56.

Gilliland, M. W. and W. Baxter-Potter. 1987. A geographic information system to predict non-point source pollution potential. Water Resources Bulletin 23:3:281291.

Harbor, J.M. 1994. A practical method for estimating the impact of land-use change on surface runoff, goundwater recharge and wetland hydrology, Journal of the American Planning Association 60:1:95-108.

Hough, R. 1995. Integrating a River Basin: Toward a systems approach to global monitoring. Environmental Science Research 50 pp.

LaGro, J. A. Jr. and S. D. DeGloria. 1992. Land use dynamics within an urbanizing nonmetropolitan county in New York State (USA). Landscape Ecology 7:4:275-289.

Landis, J., 1995. Imagining land use futures. Journal of the American Planning Association 61(4), 438-457.

Liu, D.S., L. Iverson, and S. Brown, 1993. Rates and patterns of deforestation in the Phillipines: Application of GIS analysis. Forest Ecology and Management 57, $1-16$.

McClintock, K.A., J. M. Harbor, and T. P. Wilson. 1995. Assessing the hydrological impact of land use change in wetland watersheds: a case study from northern Ohio, USA. Pages 107-119 in Geomorphology and Land Management in a Changing Environment, D.F.M. McGregor and D. A. Thompson (eds.). John Wiley \& Sons Ltd.

McMillen, D. P. and J. F. McDonald. 1998a. Suburban subcenters and employment density in metropolitan Chicago. Journal of Urban Economics 43:157-180.

McMillen, D. P. and J. F. McDonald. 1998b. Population density in suburban Chicago: a bid-rent approach. Urban Studies 35:7 forthcoming.

McGrath, D., forthcoming. Urban industrial land redevelopment and contamination risk. Journal of Urban Economics.

Mertens, B. and E. Lambin, 1997. Spatial modeling of deforestation in southern Camaroon, Applied Geography 17(2), 143-162.

Muller, M. R. and J. Middleton. 1994. A markov model of land-use change dynamics in the Niagara region, Ontario, Canada. Landscape Ecology 9:2:151-157.

Munneke, H. 1996. Redevelopment decisions for commercial and industrial properties. Journal of Urban Economics. 39:229-253.

O'Sullivan, A. 1996. Urban Economics. Boston: Richard D. Irwin.

Pijanowski, P.L. Machemer, S.H.Gage, and D.T. Long 1996. A spatially-explicit land 
use change model. Michigan State University Working Paper.

Rosenthal, S.S. and R. W. Helsley 1994. Redevelopment and the urban land price gradient. Journal of Urban Economics 35:182-200.

Spulber, N., 1998. The Economics of Water Resources: From Regulation to Privatization. Boston, Klewer Academic Publishers.

Tim, U. S., S. Mostaghimi, and V. O. Shanholtz, 1992. Identification of critical nonpoint pollution source areas using geographic information systems and water quality modeling. Water Resources Bulletin 28: 877-887.

USEPA. 1982. Another look: national survey of pesticides in drinking water wells: Phase II Report. Technical Report USEPA 579/09-91-020, USEPA, EPA Washington, DC.

USEPA, 1983. Results of the National Urban Runoff Program. Vol. 1. USEPA, Washington, D.C.

Vaillancourt, F. and L. Monty. 1985. The effect of agricultural zoning on land prices, Quebec, 1975-1981. Land Economics 61 (February): 37-42.

Wheaton, W. C. 1982. Urban spatial development with durable but replaceable capital. Journal of Urban Economics 12:53-67. 
